\section{ambient SCIENCE \\ Vol. 04(Sp1):36-40 \\ Year 2017}

\title{
Cut-off Point of Waist-circumference for Metabolic Syndrome Components among Turkman and Non-Turkman Ethnic Adults in the North of Iran
}

\section{Gholamreza Veghari ${ }^{1 *}$, Mehdi Sedaghat ${ }^{2}$, Samieh Banihashem², Pooneh Moharloei', Abdolhamid Angizeh², Ebrahim Tazik², Abbas Moghaddami², Khadijeh Kordy², Mohammadreza Honarvar ${ }^{3}$, Masoumeh Vaghari $^{4}$}

'Ischemic Disorders Research Centre, Golestan University of Medical Sciences, Gorgan, Iran

${ }^{2}$ Department of Health, Golestan University of Medical Sciences, Gorgan, Iran

${ }^{3}$ Department of Nutrition, Golestan University of Medical Sciences, Gorgan, Iran

${ }^{4}$ Pardis Student Research Committee, Golestan University of Medical Sciences, Gorgan, Iran

Study Area: Gorgan, Iran

Coordinate: $36^{\circ} 50^{\prime} 19^{\prime \prime} \mathrm{N} ; 54^{\circ} 26^{\prime}{ }^{\circ} 5^{\prime \prime E}$

Key words: HDLc, LDLc, Cholesterol, TG, FBS.

\begin{abstract}
The MetS (metabolic syndrome) is one of the main risk factors for cardiovascular disease and obesity is one of the major markers of its progression. The aim of this study was to know the comparative differences of waist circumference while predicting the relevant optimal cut-off in Turkman and non-Turkman people in the north of Iran. In our study 248 subjects aged $25-70$ years have been chosen from 25 clusters with 10 cases. ATP-III method was used for diagnosis of MetS. The optimal cut-off and the corresponding sensitivity and specificity for age have estimated in the threshold that maximizes the sum of sensitivity and specificity or equivalently maximizes in ROC (receiver operating characteristic) curve operating points. The statistical differences were significant between Turkman and non-Turkman groups in almost all the parameters such as HDLc, LDLc, cholesterol, TG, and FBS. In non-Turkman group, the association between WC and TG, LDLc and FBS showed a positive relationship but it was negative with HDLc. The association between WC and cholesterol level was not significant. The cut-off values of WC for hyper TG, HDLc low and diabetes was respectively higher 6.0, 7.25 and $8.25 \mathrm{~cm}$ in non-Turkman group than in Turkman group, however; based on hypercholesterolemia and LDLc it was lower in non-Turkman than in Turkman group. The differences in the above parameters while comparing separately between male and females is also found interesting. Conclusively, the gene has a protective role based on the cholesterol in Turkman people.
\end{abstract}

al., 2014). The prevalence of obesity and MetS depends on ethnicity and gender in Russians was more common than in the Chuvashes population (Markova et al., 2014). In the eastern Slovakia the MetS components were differently prevalent between Roma and non-Roma subjects (Fedacko et al., 2014). Previous studies in the north of Iran reported the obesity in Turkman ethnic group less than in Fars-native subjects (Veghari et al., 2010; Veghari \& Mansurian, 2007).

In the recent years, changing of lifestyle and feeding behaviours extensively increases the cardiovascular disease, diabetes mellitus, and other MetS indices in worldwide, especially in developing countries (Alwan, 2010). Blood pressure, diabetes mellitus, lipid and fasting were identified as the cardiometabolic risk factors (Guo et 
blood glucose levels are all related with central adiposity level (Shah et al., 2014).

In some studies, WC (Waist Circumference) has been reported as a better predictor of CVD risk factor (Ali et al., 2014), whereas others had recommended the WHR (Waist-hip ratio) and WHtR (WC-to-height ratio) indices (Ko et al., 1999). In the other hand, WC is well known as a better predictor of CVD than BMI (Body Mass Index) and WHR (Lin et al., 2002). Visceral adiposity is also helpful in assessing cardiovascular risk, not considering of age, race, or BMI, and can serve as an indicator and target of therapy in cardiometabolic disease (Shah et al., 2014).

Area under the ROC (receiver operating characteristic curve) is useful in evaluating the discriminatory ability of a test to properly select positive and negative disease subjects; detection optimal cut-off point to the minimum amount misclassify diseased or non-diseased subjects; comparing the efficacy of two or more tests for assessing the same disease and comparing two or more observers measuring the same test (Kumar \& Indrayan, 2011).

Golestan province located in the north of Iran (Southeast of Caspian sea) and 1,7 million people live in this area, $43.9 \%$ live in rural areas and whose main job is agriculture. In addition, three huge ethnic groups; Fars-native, Turkman and Sisstani are inhabiting in the north of Iran (SCI, 2012).

In spite of high prevalence of MetS in the north of Iran (Veghari et al., 2017) and positive association with MetS components, there are no regional optimal cut-off values of MetS components for predicting of MetS in this area. The information related to the capacity of MetS components are always useful for assessing of MetS. In this regard, the main aim of this study is to compare the discriminative capacity of MetS components in prediction of non-adipose components and to determine its relevant optimal cut-off in North Iranian adults based on ethnicity.

\section{Methodology:}

The study was approved by Ethical Research Committee and consent was received from all participants. This crosssectional study has been carried out on 248 adult subjects aged between 25-70 years. The required sample size by the previous study with estimation of $20 \%$ MetS rate; a confidence level of $95 \%$ and a maximum marginal error 0.05, was calculated 246 cases (Sharifi et al., 2009). Subjects were chosen randomly from 25 clusters and each cluster comprised 10 cases of two districts; Kordkoy and Kalaleh from Golestan province (north of Iran and southeast of Caspian Sea). The clusters were chosen randomly using systematic sampling technique based on postal code. A trained staff recorded the data continuously for the three months. Pregnant women and individuals who refused to participate were excluded from this study. The proportions of Turkman and non-Turkman ethnic groups were $88(35.5 \%)$ and $160(65.5 \%)$ cases, respectively.
Waist circumference (WC) was measured to the nearest $0.5 \mathrm{~cm}$ at the superior border of the iliac crest with the subject standing, at the end of normal breathing. Blood pressure was measured by a mercury sphygmomanometer for three times and $5 \mathrm{ml}$ of venous blood drawn after 8-12 $\mathrm{h}$ fast in the morning for laboratory test. Biochemical analysis including fasting blood glucose, triglyceride and HDL-cholesterol was assessed using a commercially kit (Pars Azmoon, Karaj, Iran).

The considered ethnic groups consist of two types:

1) Turkman: The inter-marriage of this ethnic group with others was rare and this group can be distinguished by phenotype.

2) non-Turkman: Included all of the ethnic groups (except Turkman) living in this area.

ATP-III method was used for diagnosis of MetS (Singh \& Sinha, 2016). According to this criteria, the presence of at least three of five the following criteria were included as MetS: (i) Abdominal obesity as measured by $W C>102 \mathrm{~cm}$ in men and $>88 \mathrm{~cm}$ in women; (ii) Triglycerides $>150 \mathrm{mg} / \mathrm{dl}$; (iii) HDL cholesterol $<40 \mathrm{mg} / \mathrm{dl}$ in men and $<50 \mathrm{mg} / \mathrm{dl}$ in women; (iv) SBP-systolic blood pressure $=130$ or DBPdiastolic blood pressure $=85 \mathrm{~mm} / \mathrm{Hg}$; (v) fasting plasma glucose $=110 \mathrm{mg} / \mathrm{dl}$.

Statistical Analysis: SPSS 16.o software (Chicago II, USA) was used for the statistical analysis using chi-square test and t.test for comparing frequencies and the means, respectively. P-value $<0.05$ considered as statistically significant. The optimal cut-offs and the corresponding sensitivity and specificity for age were estimated in the threshold that maximizes the sum of specificity and sensitivity or equivalently maximizes in ROC curve operating points.

\section{Results:}

Demographic characteristics of the subjects have been present in Table-1 and the comparison of Mets components between Turkman and non-Turkman based on gender has been present in Tables-2 \& 3. Both in men and women, the mean of HPLc was seen to be more in Turkman group, however; the mean of WC, FBS, LDLc and Cholesterol level significantly more in women nonTurkman group. Following the way, the significant difference was seen more in non-Turkman group only based on WC index in men ( $\mathrm{p}<0.05$ forall).

The mean and standard deviation of biochemical profile and WC cut-off for them with regression quotient presented in Table-4. The statistical differences were significant between Turkman and non-Turkman groups based on the mean of HPLc $(\mathrm{p}=<.006)$, LDLc $(\mathrm{p}<0.028)$, cholesterol $(\mathrm{p}<0.016)$, TG $(\mathrm{p}<0.015)$ and FBS $(\mathrm{p}<0.001)$. The values profiles were reported to be high in nonTurkman than in Turkman except for the level of cholesterol. While analyzed the data separately for men 
and women all such differences were evidenced mainly in women group. The men group alone shown the statistical differences only in HSLc $(\mathrm{p}<0.047)$ and WC $(\mathrm{p}<0.005)$. In pooled data, the positive and significant association was seen between TG, cholesterol, LDLc and FBS with WC ( $p<0.05$ for all), however; this association based on HDLc was negative but was not statistically significant. In nonTurkman group, the association between $\mathrm{WC}$ and TG, LDLc and FBS were positive signif icant $(\mathrm{p}<0.05$ for all) but it was negative with HDLc $(\mathrm{p}<0.001)$. The association between WC and cholesterol level was not significant. The cut-off values of WC for hyper TG, HDLc low and diabetes was respectively higher $6.0,7.25$ and $8.25 \mathrm{~cm}$ in nonTurkman group than in Turkman group, however, based on hypercholesterolemia and LDLc it was lower in nonTurkman than in Turkman group.

The AUCs ranged from 0.731 in Turkman group to 0.811 for the non-Turkman group. The values for AUC tended to be higher in non-Turkman and in total subjects (Fig.-1).

Table 1: Demographic characteristics of subjects

\begin{tabular}{|c|c|c|c|c|}
\hline \multicolumn{2}{|c|}{$\overline{\text { Variable }}$} & Turkman $(\mathrm{n}=88)$ & \multirow{2}{*}{$\frac{\text { Non-Turkman }(\mathrm{n}=160)}{67(41.9)}$} & \multirow{2}{*}{$\frac{\text { P-value }}{0.619^{*}}$} \\
\hline Sex & Men & $34(38.6)$ & & \\
\hline $\mathrm{N}(\%)$ & Women & n $54(61.4)$ & $93(58.1)$ & \\
\hline \multicolumn{2}{|c|}{ Age (Year) } & $43.9 \pm 13.6$ & $47.6 \pm 13.8$ & $0.046^{* *}$ \\
\hline \multicolumn{2}{|c|}{$\mathrm{WC}(\mathrm{cm})$} & $91.1 \pm 15.2$ & $97.6 \pm 13.9$ & $0.001^{* *}$ \\
\hline
\end{tabular}

Table 2. The comparison of Mets components (mean \pm SD) between Turkman and non-Turkman (male)

\begin{tabular}{lllllll}
\hline Subject & TG $^{*}$ & Chol $^{*}$ & LDLC $^{*}$ & HDLc $^{*}$ & FBS* & WC $(\mathrm{cm})$ \\
\hline Turkman & 126.8 & 162.19 & 96.53 & 49.8 & 91.1 & 89.5 \\
$(\mathrm{~N}=34)$ & \pm 72.7 & \pm 38.69 & \pm 29.48 & \pm 11.9 & \pm 15.5 & \pm 16.1 \\
Non-Turk & 158.3 & 170.21 & 100.19 & 45.2 & 107.6 & 97.9 \\
$(\mathrm{~N}=67)$ & \pm 103.5 & \pm 37.91 & \pm 21.41 & \pm 11.7 & \pm 50.4 & \pm 12.9 \\
p-value & 0.116 & 0.324 & 0.478 & 0.047 & 0.064 & 0.005 \\
\hline
\end{tabular}

$$
{ }^{*} \mathrm{mg} / \mathrm{dl}
$$

Table 3. The comparison of Mets components (mean \pm SD) between Turkman and non-Turkman (female)

\begin{tabular}{lllllll}
\hline Subject & TG* $^{*}$ & Chol $^{*}$ & LDLc $^{*}$ & HDLc $^{*}$ & FBS $^{*}$ & WC $(\mathrm{cm})$ \\
\hline Turkman & 126.7 & 169.84 & 98.23 & 56.9 & 86.7 & 92.1 \\
$(\mathrm{~N}=54)$ & \pm 79.4 & \pm 33.06 & \pm 24.5 & \pm 13.9 & \pm 13.2 & \pm 14.7 \\
Non-Turk & 156.0 & 181.81 & 107.41 & 52.0 & 101.9 & 97.3 \\
$(\mathrm{~N}=93)$ & \pm 99.8 & \pm 36.86 & \pm 24.42 & \pm 14.3 & \pm 39.4 & \pm 14.6 \\
p-value & 0.061 & 0.0498 & 0.0294 & 0.0449 & 0.007 & 0.0396 \\
\hline
\end{tabular}

${ }^{*} \mathrm{mg} / \mathrm{dl}$

\section{Discussion :}

As per our survey, there is no statistically significant relIn the present study, the WC cut-offs for MetS in nonTurkman is lower than in Turkman group. The prevalence rate of MetS is associated with some of the sociodemographic factors, lifestyle, and food behaviors besides it were varied worldwide (Alwan, 2010; Alberti et al., 2005).
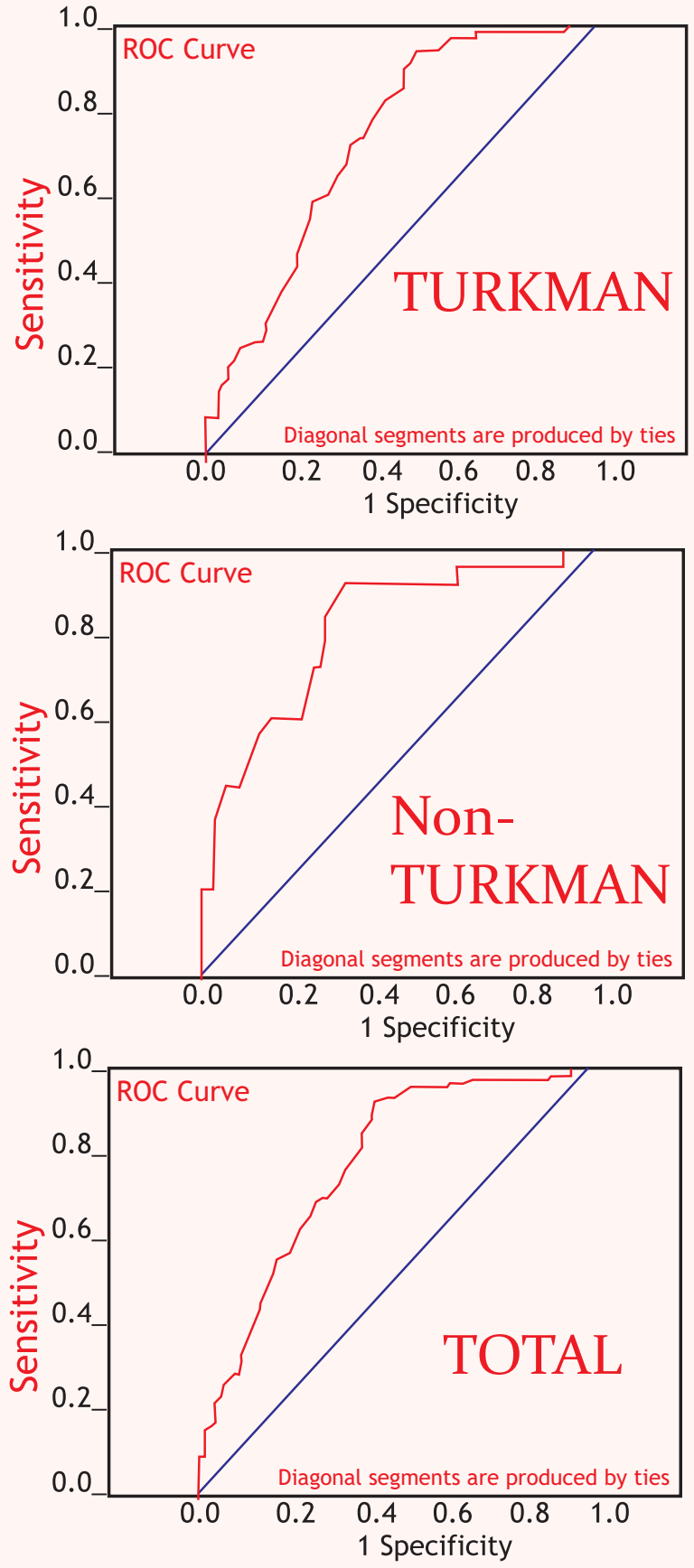

Some studies have already advocated the impact of ethnicity on the MetS components which have already been discussed in the introduction part. In nutshell, the differences in lifestyle and food behaviours among ethnic groups may influence signif icantly the cardiovascular risk factors varieties among them in the north of Iran. Establishing a comprehensive study is necessary to determine the MetS substantial factors among ethnic groups in this area.

The correlation between waist circumference and hypertension, blood glucose, and dyslipidemia as like as our study was seen in other studies (Verma et al., 2016; Gupta \& Kapoor, 2012; Zeng et al., 2014). In another study, 
Table 4: The comparison of waist circumference cut-offs value for MetS components based on ethnicity

\begin{tabular}{|c|c|c|c|c|c|c|c|c|c|c|}
\hline & Variable & $\mathrm{N}$ & Mean \pm SD & $\begin{array}{l}\text { WC } \\
\text { Cut- off }\end{array}$ & $\mathrm{RC}(ß)$ & $\mathrm{CC}(\mathrm{r})$ & P-value & $\begin{array}{l}\text { Sensitivity } \\
\text { Specificity }\end{array}$ & $\begin{array}{l}\text { RUC } \\
\text { area }\end{array}$ & Lower-Upper \\
\hline \multirow{4}{*}{ 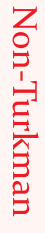 } & TG & 88 & $126.7(76.5)$ & 89.5 & 0.084 & 0.418 & 0.001 & $0.66-0.82$ & 0.767 & o.661-o.875 \\
\hline & LDLc & 88 & $96.7(25.9)$ & 93.5 & 0.171 & 0.295 & 0.001 & $0.75-0.61$ & 0.621 & $0.462-0.779$ \\
\hline & HDLc & 88 & $54.1(13.6)$ & 89.5 & -0.057 & -0.051 & 0.632 & $0.70-0.51$ & 0.567 & $0.430-0.705$ \\
\hline & FBS & 88 & $88.4(14.2)$ & 100.5 & 0.478 & 0.466 & 0.001 & $1.00-0.79$ & 0.904 & $0.822-0.987$ \\
\hline \multirow{5}{*}{ 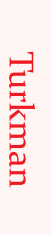 } & Chol & 160 & $176.3(37.6)$ & 85.25 & 0.043 & 0.118 & 0.133 & $0.93-0.22$ & 0.560 & $0.463-0.675$ \\
\hline & LDLc & 160 & $104.0(24.6)$ & 85.25 & 0.098 & 0.175 & 0.025 & $0.92-0.19$ & 0.459 & $0.341-0.577$ \\
\hline & HDLc & 160 & $49.2(13.7)$ & 96.75 & -0.307 & -0.304 & 0.001 & $0.71-0.57$ & 0.638 & $0.554-0.723$ \\
\hline & FBS & 160 & $104 \cdot 3(44 \cdot 3)$ & 108.75 & 0.055 & 0.173 & 0.006 & $0.40-0.84$ & 0.659 & $0.531-0.787$ \\
\hline & MetS & 160 & & 90.5 & & & & $0.54-0.94$ & 0.731 & $654-0.807$ \\
\hline
\end{tabular}

WC=waist circumference, $\mathrm{TG}=$ Triglyceride, $\mathrm{Chol}=$ Cholesterol, $\mathrm{FBS}=$ Fasting blood glucose, MetS=Metabolic syndrome

Result of t.test between two ethnic groups based on $\operatorname{HDLc}(\mathrm{P}=0.006), \operatorname{LDLc}(\mathrm{P}=0.028), \mathrm{Chol}(\mathrm{P}=0.016), \mathrm{TG}(\mathrm{P}=0.015), \mathrm{FBS}(\mathrm{P}=0.001)$

the association between abdominal obesity and hyperglycemia is stronger than in the presence of a parental history of diabetes (van Dam et al., 2001). In our study, waist circumference cut-off values for hypercholesterolemia and low HDLc in Turkman was higher than in non-Turkmangroups.

Among Iranian men, the WC cut-off values for hypertriglycredimia, low HDLc and diabetes mellitus has been reported 94.5, 94.5 and $95.5 \mathrm{~cm}$, respectively (Gharipour et al., 2013). In India, the WC cut-off values for diabetes mellitus was $<90 \mathrm{~cm}$ in Hindu Priests group (Sharma \& Sarmah, 2015). In a study in Malaysia, the cutoff values of waist circumference for Malay, Chinese and Indians based on dyslipidemia were $87.0,83.0$ and $91.0 \mathrm{~cm}$ and based on diabetes mellitus were 88.0, 77.0 and 86.0 $\mathrm{cm}$, respectively (Zaher et al., 2009). Asian people are more disposed to obesity-related co-morbidities than Caucasians people even at lower BMI and smaller WC values (Snehalatha et al., 2003). In Japan, optimal WC cutoffs was seen $89.5 \mathrm{~cm}$ for men and $82.3 \mathrm{~cm}$ for women (Oka et al., 2008). In Indian adults, cut-offs $90 \mathrm{~cm}$ and $80 \mathrm{~cm}$ recommend for men and women, respectively (Misra et al., 2005) nevertheless, the appropriate WC cut-off point for abdominal obesity in Koreans was determined to be $90 \mathrm{~cm}$ for men and $85 \mathrm{~cm}$ for women (Lee et al., 2007). For Thai adults, the cut-off $84 \mathrm{~cm}$ is the most appropriate for both men and women (Aekplakorn et al., 2006). Data from rural areas in Iraq suggests cut-offs $99 \mathrm{~cm}$ and $97 \mathrm{~cm}$ for women and men, respectively (Mansour et al., 2007). Our cut-offs are closer to the Japanese and Korean data than to those from Iraq.

In a meta-analytic study, the combined AUC for predicting diabetes mellitus typez in men was obtained 0.672 for BMI, 0.701 for WC, 0.721 for waist to hip ratio and 0.726 for waist-to-height ratio (Lee et al., 2008).

The gender differences and a proper statistical test for considering of design effect caused by cluster sampling have not used in present study. They are our limiting study factors.

Conclusively, the cut-off value of WC for MetS in Turkman group is higher than in non-Turkman group (90.5 vs 89.5). The WC cut-off values for all of MetS indices in Turkman group is higher than in non-Turkman group, but it is inverse based on cholesterol level. It seems the genetic has a protective role based on cholesterol in Turkman subjects. Well-designed and rigorous studies that employ large sample sizes are necessary to corroborate this finding.

\section{Acknowledgements:}

This study based on 239670 official documents was justified for publication and created from provincial non-communicable data study. The authors would like to thank the medical and administrative staff in the Primary Health Care Centers for their valuable assistance during the field work. This study financially has been supported by Health Office of Golestan University of Medical Sciences.

\section{References:}

Aekplakorn, W., Kosulwat, V. \& Suriyawongpaisal, P. (2006): Obesity indices and cardiovascular risk factors in Thai adults. Int. J. Obes. (Lond)., 30(12):1782-1790.

Alberti, K.G., Zimmet, P. \& Shaw, J. (2005): IDF Epidemiology Task Force Consensus Group. The metabolic syndrome: a new worldwide definition from the international diabetes federation consensus. Lancet, 366:1059-1062.

Ali, O., Cerjak, D., Kent, J.W. Jr., James, R., Blangero, J., Zhang, Y. (2014): Obesity, central adiposity and cardiometabolic risk factors in children and adolescents: a family-based study. Pediatr. Obes., 9(3):e58-62.

Alwan, A. (2011): Global status report on noncommunicable diseases. 2010; WHO.

Bentley, A.R., Chen, G., Shriner, D., Doumatey, A.P., Zhou, J., Huang, H., Mullikin, J.C., Blakesley, R.W., Hansen, N.F., Bouffard, G.G., Cherukuri, P.F., Maskeri, B., Young, A.C., Adeyemo, A. \& Rotimi, C.N. (2014): Gene-based sequencing identifies lipid-influencing variants with ethnicity-specific 
effects in African Americans. PLoS Genet. 10(3):e100419o.

Fedacko, J., Pella, D., Jarcuska, P., Siegfried, L., Janicko, M., Veselíny, E., Sabol, F., Jarcuska, P., Mareková, M., Gecková, A.M., Pazinka, P., Jankajová, M., Kmec, J., Babcák, M., Kalanin, P. \& Drazilová, S. (2014): Clinical and biochemical determinants of metabolic syndrome among Roma and nonRoma subjects in the eastern part of Slovakia. Cent. Eur. J. Pub. Health, 22(S):75-80.

Gharipour, M., Sarrafzadegan, N., Sadeghi, M., Andalib, E., Talaie, M., Shafie, D. \& Aghababaie E. (2013): Predictors of metabolic syndrome in the Iranian population: waist circumference, body mass index, or waist to hip ratio? Cholesterol, 2013:198384.

Guo, X., Li, Z., Guo, L., Zheng, L., Yu, S., Yang, H., Zou, L., Zhou, Y., Zhang, Y., Zhu, L., Zhang, Y. \& Sun, Y. (2014): An update on overweight and obesity in rural Northeast China: from lifestyle risk factors to cardiometabolic comorbidities. $\underline{B M C}$ Pub. Health, 14:1046.

Gupta, S. \& Kapoor, S. (2012): Optimal cut-off values of anthropometric markers to predict hypertension in North Indian population. J. Community Health. 37(2):441-447.

Ko, G.T.C., Chan, J.C.N., Cockram, C.S., \& Woo, J. (1999): Prediction of hypertension, diabetes, dyslipidemia or albuminuria using simple anthropometric indexes in Hong Kong Chinese. Int.J. Obesity, 23(11):1136-1142.

Kumar, R. \& Indrayan, A. (2011): Receiver operating characteristic (ROC) curve for medical researchers. Ind. Pediatr., 48(4):277287.

Lee, C.M.Y., Huxley, R.R., Wildman, R.P. \& Woodward, M. (2008): Indices of abdominal obesity are better discriminators of cardiovascular risk factors than BMI: a meta-analysis. J Clin Epidemiol., 61(7):646-653.

Lee, S.Y., Park, H.S., Kim, D.J., Han, J.H., Kim, S.M., Cho, G.J., Kim, D.Y., Kwon, H.S., Kim, S.R., Lee, C.B., Oh, S.J., Park, C.Y. \& Yoo, H.J. (2007): Appropriate waist circumference cutoff points for central obesity in Korean adults. Diabetes Res. Clin. Pract., 75(1):72-80.

Lin, W.Y., Lee, L.T., Chen, C.Y., Lo, H., Hsia, H.H., Liu, I.L., Lin, R.S., Shau, W.Y. \& Huang, K.C. (2002): Optimal cut-off values for obesity: using simple anthropometric indices to predict cardiovascular risk factor in Taiwan. Int. J Obes., 26(9):12321238.

Mansour, A.A., Al-Hassan, A.A. \& Al-Jazairi, M.I. (2007): Cut-off values for waist circumference in rural Iraqi adults for the diagnosis of metabolic syndrome. Rural Remote Health., 7(4):765.

Markova, T.N., Kichigin, V.A., Madianov, I.V., Semakina, S.M. \& Diomidova, V.N. (2014): Hormonal aspects of the development of obesity and metabolic syndrome in ethnic groups (by the population of the Chuvash Republic). Ter Arkh. 86(5):73-77. [Russian].

Misra, A., Wasir, J.S. \& Pandey, R.M. (2005): An evaluation of candidate definitions of the metabolic syndrome in adult Asian Indians. Diabetes Care., 28(2):398-403.

Oka, R., Kobayashi, J., Yagi, K., Tanii, H., Miyamoto, S., Asano, A., Hagishita, T., Mori, M., Moriuchi, T., Kobayashi, M., Katsuda, S., Kawashiri, M.A., Nohara, A., Takeda, Y., Mabuchi, H. \& Yamagishi, M. (2008): Reassessment of the cutoff values of waist circumference and visceral fat area for identifying Japanese subjects at risk for the metabolic syndrome. Diabetes Res. Clin. Pract., 79(3):474-481.
SCI (2012): Population and Housing Census [Online], Pub. By: Statistical Center of Iran. Available from: URL: http://www.amar.org.ir/Portals/1/Iran/census-2.pdf

Shah, R.V., Murthy, V.L., Abbasi, S.A., Blankstein, R., Kwong, R.Y., Goldfine, A.B., Jerosch-Herold, M., Lima, J.A., Ding, J. \& Allison, M.A. (2014): Visceral adiposity and the risk of metabolic syndrome across body mass index: the MESA Study. JACC Cardiovasc. Imaging., 7(12):1221-1235.

Sharifi, F., Mousavinasab, S.N., Saeini, M. \& Dinmohammadi, M. (2009): Prevalence of metabolic syndrome in an adult urban population of the west of Iran. Exp. Diabetes Res., 2009:136501.

Sharma, B. \& Sarmah, D. (2015): WC is better than BMI as a predictor of diabetes and prediabetes in Hindu priests of India. Asian J. Med. Sci., 6(1):91-94.

Singh, A., \& Sinha, N. (2016): Metabolic Syndrome: Can We Keep Check?.J. Obstet. Gynaecol. India., 66(6):466-470.

Snehalatha, C., Viswanathan, V. \& Ramachandran, A. (2003): Cutoff values for normal anthropometric variables in asian Indian adults. Diabetes Care., 26(5):1380-1384.

van Dam, R.M., Boer, J.M., Feskens, E.J. \& Seidell, J.C. (2001): Parental history of diabetes modifies the association between abdominal adiposity and hyperglycemia. Diabetes Care., 24(8):1454-1459.

van Herpt, T.T.W., Dehghan, A., van Hoek, M., Ikram, M.A., Hofman, A., Sijbrands, E.J.G. \& Franco, O.H.F. (2016): The clinical value of metabolic syndrome and risks of cardiometabolic events and mortality in the elderly: the Rotterdam study. Cardiovasc. Diabetol., 15:69.

Veghari, G. \& Mansurian, A.R. (2007): Obesity Among Mothers In Rural Golestan-Iran ( south - east of Caspian sea). Iran. J. Pub. Health, 36(3):71-76.

Veghari, G., Sedaghat, M., Joshaghani, H., Hoseini, A., Niknajad, F., Angizeh, A., Tazik, E. \& Moharloei, P. (2010): The prevalence and associated factors of central obesity in Northern Iran. Iran. Cardiovas. Res. J., 4(4):164-168.

Veghari, G., Sedaghat, M., Banihashem, S., Moharloei, P., Angizeh, A., Tazik, E., Moghaddami,, A., Kordy, K. \& Honarvar, M. (2017): Age Cut-off Point for the Diagnosis of Metabolic Syndrome in Northern Adult Iranians: A New Approach in Prevention. Ambient Sci., o4(Sp1): Online.

Verma, M., Rajput, M., Sahoo, S.S., Kaur, N. \& Rohilla, R. (2016): Correlation between the percentage of body fat and surrogate indices of obesity among adult population in rural block of Haryana. J. Family Med. Prim. Care., 5:154-159.

Vishram, J.K. (2014): Prognostic interactions between cardiovascular risk factors. Dan Med J.,61(7):B4892.

Zaher, Z.M., Zambari, R., Pheng, C.S., Muruga, V., Ng, B., Appannah, G. \& Onn, L.T. (2009): Optimal cut-off levels to def ine obesity: body mass index and waist circumference, and their relationship to cardiovascular disease, dyslipidaemia, hypertension and diabetes in Malaysia. Asia Pac.J. Clin. Nutr., 18(2):209-216.

Zeng, Q., He, Y., Dong, S., Zhao, X., Chen, Z., Song, Z., Chang, G., Yang, F. \& Wang, Y. (2014): Optimal cut-off values of BMI, waist circumference and waist: height ratio for defining obesity in Chinese adults. Br. J. Nutr., 112(10):1735-1744. 